УДК 902

https://doi.org/10.24852/2587-6112.2021.3.65.79

\title{
К ВОПРОСУ О ДАТИРОВКЕ ОСТОЛОПОВСКОГО СЕЛИЩА В TATAРСТАНЕ
}

\author{
(C) 2021 г. К.А. Руденко
}

В статье рассматриваются вопросы датировки Остолоповского селища в Республике Татарстан. Селище располагалось в центральной части Волжской Булгарии и было связано с крупными городами этого государства. С 1955 г. оно разрушается Куйбышевским водохранилищем. Селище исследовалось в 1969 г. казанским археологом Т.А. Хлебниковой. Она считала, что селище возникло в Х в., возможно, в конце IX в. и существовало до XII в. В 1991 г. Е.П. Казаков высказал мнение, что это селище возникло не ранее второй половины X в. Задача данной статьи - сделать заключение о времени возникновения этого селища. Для этого был использованы артефакты, собранные с 1980-х гг. и до 2000-х гг. из разрушенного культурного слоя, а также из раскопок на селище, которые проводил в 1997-2017 гг. К.А. Руденко. Были изучены предметы нескольких категорий. Это изделия из стекла, камня, железа и цветных металлов. Интересны стеклянные бусы, изготовленные на Ближнем Востоке, которые были распространены в Волжской Булгарии в XI-XII вв. Очень редкими являются находки на селище стеклянного перстня и браслета, датированные XI в., которые были изготовлены в Византии, миниатюрной подвески из лазурита этого же времени, а также фрагментов стеклянной лампы и парфюмерного стеклянного флакона, изготовленных в Сирии или Египте в XI-XII вв. Выявлены предметы, связанные с населением Прикамья - древними марийцами и удмуртами. Это предметы личной гигиены и украшения. Также были найдены арабские монеты Бувейхидов, выпущенных в конце X - начале XI в. Кроме этого, найдено большое количество железных артефактов, связанных с аскизской археологической культурой Южной Сибири. Они датируются второй половиной XI в. - первой половиной XII в. Таким образом, анализ артефактов показал, что Остолоповское селище возникло не ранее конца X в. Активно развивалось оно в XI - начале XII в.

Ключевые слова: археология, Волжская Булгария, датировка, селище, стратиграфия, домонгольский период, изделия из цветного металла, стеклянная лампа, бусы, аскизская культура.

\section{THE DATING ISSUE OF OSTOLOPOVO ANCIENT VILLAGE IN TATARSTAN}

\section{K.A. Rudenko}

The paper addresses the issues of dating of Ostolopovo village in the Republic of Tatarstan. The settlement was located in the central part of the Volga Bolgaria and was connected with the large cities of this state. Since 1955 it is destroyed by the Kuibyshev reservoir. The settlement was investigated in 1969 by Kazan archaeologist T.A. Khlebnikova. She was convinced that the settlement arose in the $10^{\text {th }}$ century, possibly at the end of the $9^{\text {th }}$ century, and existed until the $12^{\text {th }}$ century. In 1991, E.P. Kazakov expressed an opinion that this settlement originated not earlier than the second half of the 10th century. The purpose of this paper is to draw a conclusion about the time of emergence of this settlement. For this, artifacts were used, collected from the 1980s to the 2000s from the destroyed cultural layer, and the excavations at the settlement, carried out in 1997-2017 by K.A. Rudenko. Artifacts of several categories have been studied. These are products made of glass, stone, iron and non-ferrous metals. Of interest are the glass beads made in the Middle East, which were widespread in Volga Bolgaria in the $11^{\text {th }}-12^{\text {th }}$ centuries. Very rare items discovered on the settlement include a glass ring and bracelet made in Byzantium dated the $11^{\text {th }}$ century, a miniature lapis lazuli pendant of the same time period, and fragments of a glass lamp and a perfume glass bottle made in Syria or Egypt in the 11-12 $2^{\text {th }}$ centuries. Items related to the population of the Kama region - the ancient Mari and Udmurts - were revealed. These are personal hygiene items and jewelry. Other discovered items are Arab coins of the Buwaihids (Buyids) issued in the late $10^{\text {th }}$ - early $11^{\text {th }}$ centuries. In addition, a large number of iron artifacts associated with the Askiz archaeological culture of Southern Siberia were found. They were dated from the second half of the $11^{\text {th }}$ century to the first half of the $12^{\text {th }}$ century. Thus, an analysis of the artifacts revealed that Ostolopovo settlement did not appear earlier than the end of the 10th century. It actively developed in the $11^{\text {th }}-$ early $12^{\text {th }}$ centuries.

Keywords: archaeology, Volga Bolgaria, dating, settlement, stratigraphy, pre-Mongol period, non-ferrous metal products, glass lamp, beads, Askiz culture 
Место древнего поселения у с. Речное (ранее - Остолопово) в Алексеевском районе Татарстана было известно с XIX в. У него было местное название - «Жилище», которое предание связывало с неким татарским богатырем. Эта территория не распахивалась и использовалась только как пастбище. Возникло селение у места слияния двух рек: Шенталки (Шенталы) и её правого притока - Большой Бахты, на мысу коренной террасы, полого понижавшейся к северо-востоку. Мыс имел трапециевидную форму (рис. 1: 1, 2) и был ограничен с запада и северо-запада поймой Камы. Берег с этих сторон был обрывистый, высотой около 3-4 м. На небольшом удалении от него имелись неглубокие суходолы - следы старого русла Шенталки, которая не единожды его меняла. С юго-юго-восточной стороны мыса протекала речка Шенталка, которая чуть севернее подмыла берег, образовав в северо-восточной части останца небольшой залив (рис. 1: 2). После того как русло сменилось, в этом месте осталась старица. С юго-западной стороны, где останец переходил в коренную террасу, была глубокая и широкая лощина, которая в высокий паводок заливалась водой. Таким образом, мыс практически со всех сторон имел естественные границы.

Тем не менее этот мыс был заселен булгарами не сразу. Первоначально они выбрали место выше, на краю коренной террасы, за лощиной. Это поселение - Остолоповское Іа селище, существовало во второй половине $\mathrm{X}$ в. (Руденко, 2019, с. 106, рис. 2). По керамическим находкам оно близко поселению середины X в. в правобережье Малого Иерусалимского оврага в Булгаре (Старостин, 1993, с. 62).

После создания Куйбышевского водохранилища в 1955-1956 гг. началось интенсивное разрушение останца (рис. 1: 3). В 1960 г. Т.А. Хлебникова зафиксировала на мысу следы булгарского поселения (I Остолоповское селище). Она повторно обследовала его в 1967 г., а в 1969 г. провела здесь раскопки на площади 64 кв. м (Хлебникова, Казаков, 1976, c. 126; Хлебникова, 1970; Хлебникова, 1974, с. 58-68). Её раскоп находился «посередине югоюго-восточной части края острова, у обрыва к реке, где прослеживался довольно мощный культурный слой с ямами» (Хлебникова, 1970, л. 6) (рис. 2: 4). На момент разведок и раскопок в 1960-х гг. площадь селища составляла около 61500 кв. м с учетом начавшегося разрушения берега в 1955-1957 гг. (Хлебникова, 1970; Археологические, 1988, с. 47, № 295). В 2005 г. останец занимал 25310 кв. м (рис. 2: 3), т. е. за 47 лет его площадь сократилась почти в 2,5 раза (Гайнуллин, Дёмина, Усманов, 2012, c. 62). За прошедшие 15 лет площадь селища уменьшилась еще на треть.

По данным исследований 1960-х гг. Т.А. Хлебникова датировала Остолоповское селище X-XI вв. При этом она сделала оговорку, что оно возникло оно на рубеже IX-X в. В этом предположении она исходила из аналогий ряду керамических форм из ямы № 4 раскопа 1969 г., которую она считала самой ранней, «восходящей дневным уровнем к основанию культурного слоя булгарской эпохи» (Хлебникова, 1974, с. 61). Это материалы Танкеевского могильника и хазарского слоя Саркела (Хлебникова, Казаков, 1976, с. 126, прим. 104). Впрочем, находки из жилища, которое полностью попало в раскоп, и культурного слоя, которые и стали основанием для определения времени существования всего селища (Хлебникова, 1974, с. 59, рис. 1), в настоящее время датируются более поздним временем (Руденко, 2017, с. 298). В сущности, практически единственной датирующей находкой из раскопок Т.А. Хлебниковой является бронзовый наконечник пояса, который по материалам могильников Марийского Поволжья и Пермского Прикамья относится ко второй половине X - XI в., в большей степени XI в., например: «Черемисское кладбище» (погр. 6), «Нижняя стрелка» (погр. 4, 11, 11a, 15, 16) или Огурдинский могильник (погр. 166), датированный рубежом X-XI - 2 пол. XI в. (Никитина, 2012, с. $202,244,257,263,266$, рис. 96 : 9, 10; 138: 13, 14; 151:12, 13; 157: 12; 160: 11, 13; Белавин, Крыласова, 2012, с. 120, 179, 214 , 218 , рис. $68: 21 ; 50: 10)$.

В конце 1980-х гг. Е.П. Казаков, занимавшийся исследованиями булгарских селищ нижнего течения Камы, высказал мнение о более поздней датировке Остолоповского поселения, соотнеся начало его функционирования с возникновением торгово-ремесленных булгарских поселений в приустьевой части Камы во второй половине X - первой половине XI в. (Казаков, 1991, с. 161).

Таким образом, вопрос о времени возникновения Остолоповского селища остается открытым. Если изученные раскопками в 1997-2017 гг. участки территории датируются не ранее конца Х в. (Руденко, 2017, с. 306, 307), то когда функционировала та часть поселения, которая была уничтожена водохранилищем? Обратимся к подъемному материалу с этого памятника. 


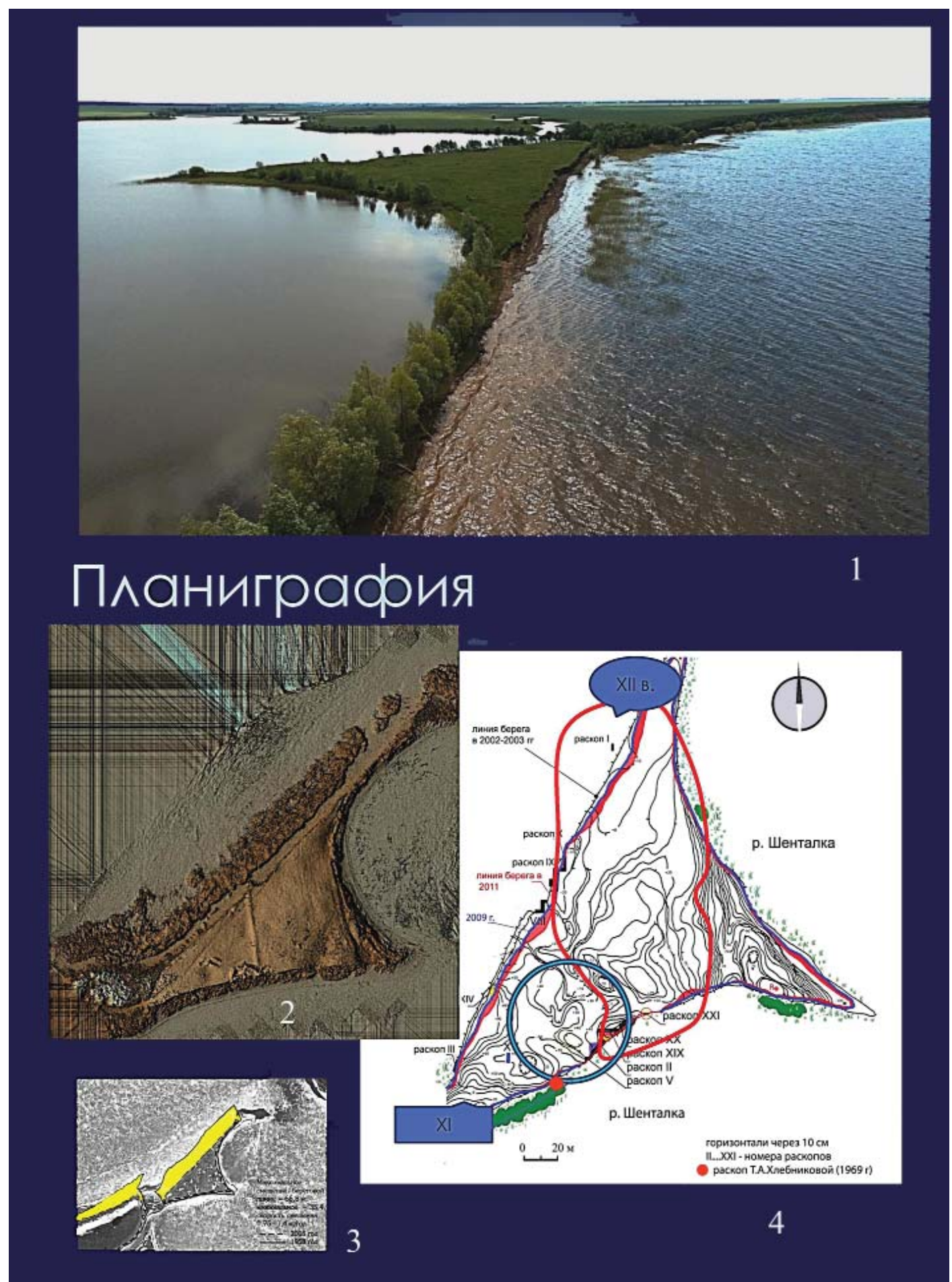

Рис. 1. Остолоповское селище. 1 - Общий вид с севера. 2 - ортофотоплан, съемка 2019 г. 3 - схема сопоставления разрушенной части памятника на состояние 2005 г. (по: Гайнуллин, Демина, Усманов, 2012). 4 - планиграфия Остолоповского селища; составлена К.А. Руденко

Fig. 1. Ostolopovo village. 1 - General view from the north. 2 orthophotomap, survey of 2019; 3 - comparative layout of the destroyed part of the monument as of 2005 (after: Gainullin, Demina, Usmanov, 2012). 4 planigraphy of the Ostolopovo settlement; compiled by K.A. Rudenko

В 1980-х - первой половине 1990-х гг. Остолоповское селище обследовали Е.П. Казаков, Е.А. Беговатов и М.М. Кавеев, затем К.А. Руденко. Ими осматривалось в основном западное побережье останца, которое активно разрушалась, в отличие от восточного и юговосточного берега, заросшего ивами, густым кустарником, камышом и менее подверженного размыву.

Интересны находки, собранные M.M. Кавеевым в 1986 г. (БГИАМЗ, коллекция № 209), происходящие, скорее всего, из разрушенной жилой постройки и прилегающих хозяйственных сооружений - центра крупной 

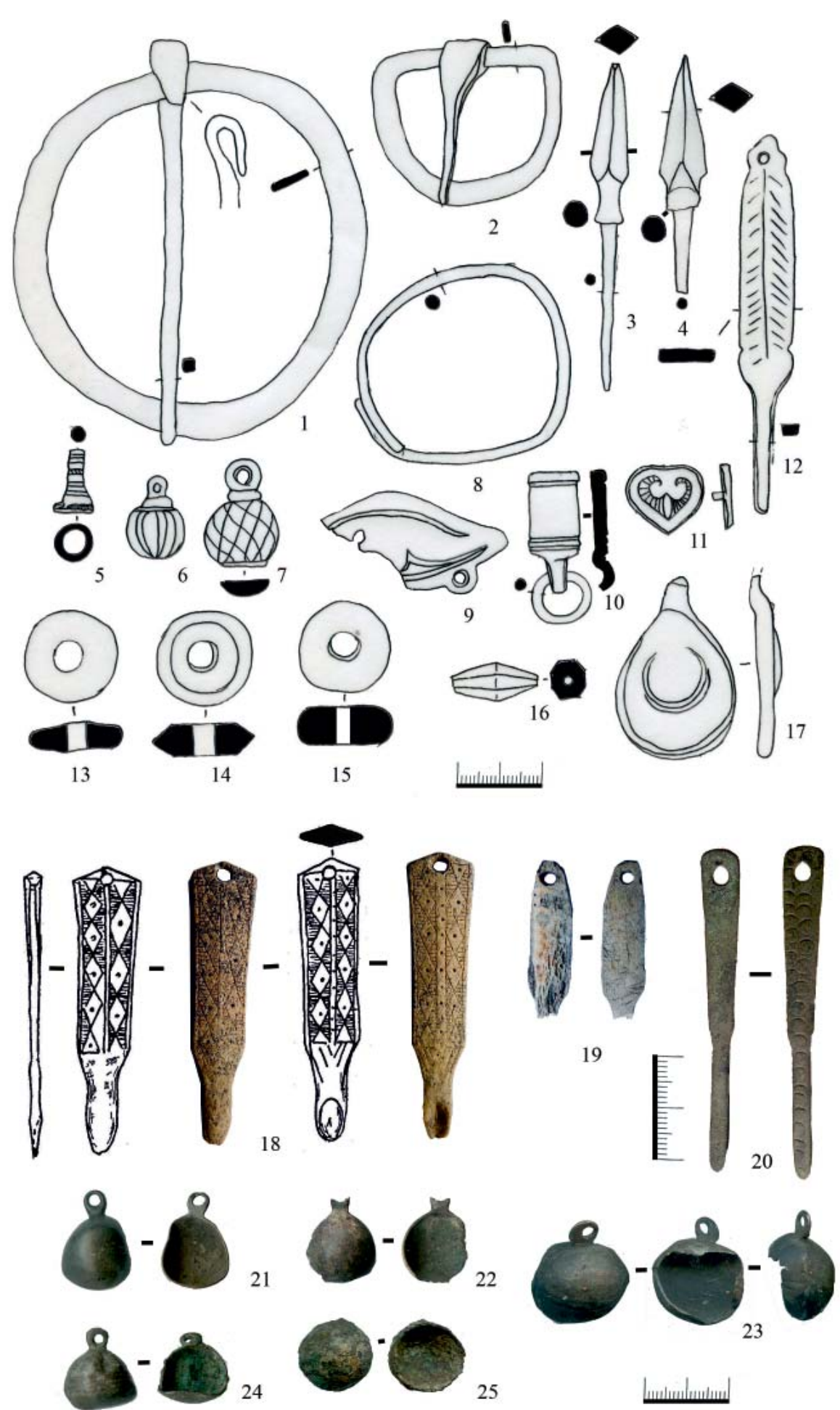

Рис. 2. Остолоповское селище. Изделия из железа (1-4), цветного металла (5-11,20-25), кости $(12,18,19)$, стекла

(17) и камня (16). 1-17: подъемный материал 1986 г., сборы М.М. Кавеева; собрание БГИАМЗ, КП № 209.

20-25: подъемный материал 1997-2005 г.; 18: раскоп XI, яма 1; 19: раскоп XXII, уч.9, пласт 3, слой IIIр

Fig. 2. Ostolopovo village. Items made of iron (1-4), non-ferrous metal (5-11, 20-25), bones (12, 18, 19), glass (17) and stone (16). 1-17: excavated material of 1986, collected by M.M. Kaveev; collection of BGIAMZ, KP No. 209.

20-25: excavated material of 1997-2005; 18: Excavation XI, pit 1; 19: Excavation XXII, section 9, layer 3, layer IIIp

усадьбы. Это фрагменты керамики - крупных тарных круговых сосудов, лепных горшков с примесью толченой раковины с верёвочногребенчатой орнаментацией (БГИАМЗ, инв. № 209/7,39). Также были найдены железные подпружные пряжки (рис. 2: 1, 2), наконечни- ки стрел XI-XII в. (рис. 2: 3, 4) и поделки из сплава цветного металла. Среди последних бронзовый проволочный браслет (рис. 2: 8), пронизка (рис. 2: 5), датированная по аналогиям второй половиной X - XI в. (Никитина, 2012 , с. 178,363 , рис. $72: 7 ; 257: 36)$, бронзовые 
накладки, одна из которых литая сердцевидная $(2 \times 1,6$ см) с изображением крина на штрихованном фоне (БГИАМЗ, инв. № 209/22) встречается в составе украшений конца X XI в. погребального инвентаря могильников Марийского Поволжья и Верхнего Прикамья (могильники Веселовский, «Черемисское кладбище»; Дубовский, Огурдинский), как и бронзовые пуговицы с рельефным орнаментом (Никитина, 2012, с. 148, 176, 218, 343, 382, рис.42: 10; 70: 14; 112: 20; 237: 6; 276: $8,9)$. Бронзовые пуговицы этот типа известны с булгарского I Измерского селища конца X XI в. (Казаков, 1991, с. 115, рис. 40: 52-55). Бронзовая накладка (рис. 2: 10) по аналогиям датируется XI в. Интересен фрагмент птицевидной (крыловидной) нашивки с шумящими привесками (рис. 2: 9) (БГИАМЗ, инв. № 209/131). Такие нашивки были распространены у гузов во второй половине X - первой половине XI в. (Путешествие, 2016, с. 197, 200, кат. 139, 142). Из бронзы был отлит диск диаметром 2,3, толщиной 0,6 см, с отверстием в центре диаметром 0,7 см (БГИАМЗ, инв. № 209/41).

Каменные изделия представлены пряслами и бусами. Прясла овальной и усеченно-биконической формы изготовлены из овручского шифера темно-малинового и розового цвета (рис. 2: 14, 15). Такого типа прясла были встречены в раскопах на селище во II-III стратиграфических слоях (Руденко, 2017, с. 314, 317, рис. 3: 7; 6: 2). Бипирамидальная, шестигранная сердоликовая бусина длиной 2 и шириной 1 см (БГИАМЗ, инв. № 209/113) датируется в широких хронологических рамках, но на памятниках Волжской Булгарии такие бусы встречаются в основном в XI-XII вв., а в Прикамье - в XI в. (Полубояринова, 1991 , с. $21,26,27$, рис. 1: 16; Голдина, Королева, 1983, с. 60, тип 164). В Мякининских курганах аналогичные бусы встречены в захоронениях XII в. (Энговатова, 2018, с. 233, 235, $237,243$, рис. $156: 1 ; 158: 3 ; 160: 8 ; 166: 16)$.

Интересна костяная копоушка (рис. 2: 12), относящаяся к типу изделий, которые встречаются в Прикамье в X-XI вв., а ранние варианты известны там с IX в. (Иванова, Куликов, 2000, 146, 210, кат. 469). Костяные копоушки найдены при раскопках селища в объектах и в слое XI-XII в. Одна из них происходит из раскопа XI (рис. 2: 18), вторая из раскопа XXII из слоя IIIр (рис. 2: 19). Эти артефакты являются репликами изделий X-XI в. поволжских и прикамских финнов (Иванова, 1998, с. 162, 163, рис. 67; Никитина, 2012, с. 162, 174,
176, 214, рис. 56: 2; 68: 2, 3; 70: 11-13; 108: 2, 4; Крыласова, 2007, с. 287, рис. 117: 10, 11, 17). Копоушки с треугольным верхним краем подтрапециевидной формы встречены в ярославских курганах X-XI вв., на Старой Ладоге и на Сарском городище (Фехнер, 1963, с. 40, 41, рис. 23: 1; Старая, 2003, с. 87, кат. 203; Леонтьев, 1996, с. 147, 149, рис. 62). Точные аналоги орнаментированной копоушки (рис. 2: 18) имеются в древнемарийском Выжумском III могильнике в погребениях 4, 5 и 21, датированных XII в. (Архипов, 1986, с. 62, рис. 22: 1-11). Также костяные копоушки встречаются на булгарских селищах второй половины X - XI в., например, на I Измерском (Казаков, 1991, с. 142, 143, рис. 46: 17-19). Известны они и на Билярском городище. На Остолоповском селище найдена бронзовая копоушка с циркульным орнаментом (рис. 2: 20). Она близка таким поделкам Пермского Прикамья X-XIII вв. (Крыласова, 2007, с. 283, рис. 116: 2, 3).

В числе находок 1986 г. с Остолоповского селища - лапка (ручка-петелька) от стеклянной лампы (рис. 2: 17), находка на булгарских домонгольских памятниках очень редкая. Она имеет каплевидную форму $(2,7 \times 4,5 \times 0,7$ см) с невысоким бортиком и небольшой выпуклой шишечкой посередине. В верхней части артефакта имеется обломанная петелька. Лапка сделана из стеклянного жгута, один конец которого был расплющен и приваривался к тулову, а другой, тонкий, прикреплялся выше к тулову лампы. Стекло её бесцветное, с легким желтоватым оттенком, патинизировано. Лампы с подобными, только меньшего размера, ручками найдены Е.А. Беговатовым на II Билярском селище в раскопе IV (яма 13) и раскопе $\mathrm{V}$ (ямы 15 и 21). Датированы они X-XI вв. (Беговатов, Полубояринова, 2014, с. 158-160, рис. 1-3). Изготавливались стеклянные лампы этого типа в Сирии или Иране, преимущественно в XI в. (Carboni, 2001, p. 166,167 , cat. 38b). Серия таких ламп происходит из раскопок Нишапура и датируется X-XI вв. (Carboni, Waitehouse, 2002, p. 20, fig. 5; Kröger, 1995, p. 182, 183, cat. 235).

Отметим, что это не единственный редкий предмет с этой усадьбы. Так, из ямы 1 раскопа XVI Остолоповского селища происходит фрагмент стеклянного парфюмерного сосуда ближневосточного или византийского производства, которые бытовали в XI-XII вв. (Столярова, 1988, с. 272-277; Руденко, 2010, с. 133, рис. 7: 1; Carboni, Waitehouse, 2002, p. 139, cat. 55). Дневной уровень ямы относит- 
ся к ІІІп слою, а заполнение к горизонту IIIа - рубежа XI-XII - первой половины XII в. (Руденко, 2012, с. 126, табл. 1). Исследованием Е.К. Столяровой установлено, что стекло для изготовления этого сосуда было сварено из трех компонентов и относится к классу $\mathrm{Na}_{2} \mathrm{O}-\mathrm{CaO}-\mathrm{SiO}_{2}$ типу $\mathrm{Na}_{2} \mathrm{O}-\mathrm{K}_{2} \mathrm{O}-\mathrm{CaO}-\mathrm{MgO}-$ $\mathrm{SiO}_{2}-\mathrm{Al}_{2} \mathrm{O}_{3}$ (Столярова, 2008, с. 274).

Судя по находкам 1986 г. и осмотрам памятника, проведенным нами в 1988-1989 гг. именно в этот период происходило разрушение центральной части этой усадьбы. Периферийная часть её стала исследоваться нами в 1997 г. Работы здесь продолжались до 2005 г., когда обрушение береговой полосы на этом участке побережья было стабилизировано.

В 1997-2005 гг. был собран подъемный материал из разрушенного за предыдущие годы культурного слоя. Он представлен керамикой, изделиями из цветного металла, железа, кости (Руденко, 2002, с. 39-42, 51, 52, рис. $6,7)$. Среди находок были пробитые монеты бувейгидов конца X - начала XI в., монетовидные подвески, рубленые кусочки серебра, имевшие хождение в конце X - XI в., части ювелирных серебряных изделий, небольшие литые серебряные слитки, а также весовые железные кубические гирьки, некоторые из них со знаками (Руденко, 2002, с. 52, рис. 7: 2-5, 42, 43, 44; Руденко, 2017, с. 305, 319, рис. 8). Отметим находку железного музыкального инструмента - варгана (кубыза) (Руденко, 2002, с. 52, рис.7: 40). Это первое такое изделие, обнаруженное на булгарских поселениях этого времени. Также в числе находок была шумящая накладка с тремя лапчатыми привесками (Руденко, 2010, с. 134, рис. 8: 7), имеющая аналогии с артефактами из могильников конца X - XI в. поволжско-финского населения (Никитина, 2012, с. 273, рис. 167: 1). К этому же кругу артефактов относятся бронзовые шаровидные и конические пронизки, пуговицы и подвески (Руденко, 2002, с. 52, рис. 7: 20, $21,22,25,26)$ (рис. 2: 21-24). Из предметов с узкой датой отметим грушевидный бубенчик с крестовидной прорезью, датирующийся по материалам Новгорода с середины X до середины XII в. (Руденко, 2002, рис. 7: 18; Седова, 1981, с. 156,157 , рис. 62: 1-5).

В 1981 г. Е.П. Казаковым на селище были собраны фрагменты медной посуды конца XI - XII в.: ушки от медных котлов, обломки венчиков и стенок от них. Аналогичный материал, хотя и не столь многочисленный, был собран нами в конце 1990-х гг. (Руденко, 2002, с. 51, рис. 6: 1-6). Судя по состоя- нию артефактов, эти фрагменты использовались как сырье. В конце 1990-х гг. здесь были найдены и разнообразные предметы вооружения: железные наконечники стрел, наконечник дротика, железные псалии, в том числе одна «крылатая», костяная петля для колчана (Руденко, 2002, с. 51, 52, рис. 6: 7, 10-13; 7: 38). Стоит отметить и оригинальный набор (12 экз.) железных пластин от доспеха (Руденко, 2002, рис. 6: 14; 7: 39), типы которых впервые были встречены на булгарских памятниках домонгольского времени. Отметим, что такие пластины были найдены и на раскопах в сооружениях и в отложениях III слоя. Стратиграфическая дата этих артефактов, как и дата по аналогиям - конец XI - первая половина ХII в. (Руденко, 2014a, с. 47-49, рис. 1).

Бусинный комплекс Остолоповского селища, по исследованиям 1997-2017 гг,, составляют артефакты из стекла и камня. Стеклянные бусы как из подъемного материала, так и из раскопов, делятся на монохромные и полихромные. Монохромные бусы представлены круглыми зонными и шаровидными полупрозрачными желтого цвета (рис. 3: 1, 2), круглыми зонными черного цвета (рис. 3: 3) и желтым бисером (рис. 3: 4), изготовленными навивкой. Они часто встречаются на средневековых памятниках Восточной Европы, в том числе и на поселениях волжских булгар, в XI-XII вв. (Доброва, 2018, с. 110, 111, рис. 4: 20; 5: 14; Захаров, 2004, рис. 283; Руденко, 2015 , с. 309,372 , рис. $60: 3-5$, I: 3в ,г, 3; XI: 9, 10). Из них довольно редки бусы черного цвета.

Полихромные бусы, изготовленные навивкой, разнообразны. Некоторые из них украшены накладными нитями белого и желтого цвета (рис. 3: 13, 14). Одна из них, самая крупная $(1,7 \times 1,5 \times 1,1 \quad \mathrm{~cm})$, треугольная, зонная, диаметром 0,8 см, с выпуклыми глазками, обведенными петлеобразной нитью, и с широким отверстием (рис. 3: 14), имеет аналоги на древнерусских памятниках XI-XII и XII в. (Захаров, 2004, рис. 298: 3, 4; Журухина, 2015, рис. VIII: 2). Глазчатые бусины цилиндрической или боченкообразной формы имеют три-четыре плоских или чуть выпуклых глазка круглой или овальной формы (рис. 3: 8-11). Цвет бусин желтый, коричневый и бирюзовый. Глазкѝ состоят из нескольких слоев стекла, например, коричневого и желтого либо белого и желтого, коричневого с синим центром и синего, желтого и черного. Они имеют аналогии как на памятниках XIXII вв. Волжской Булгарии, так и Восточной 


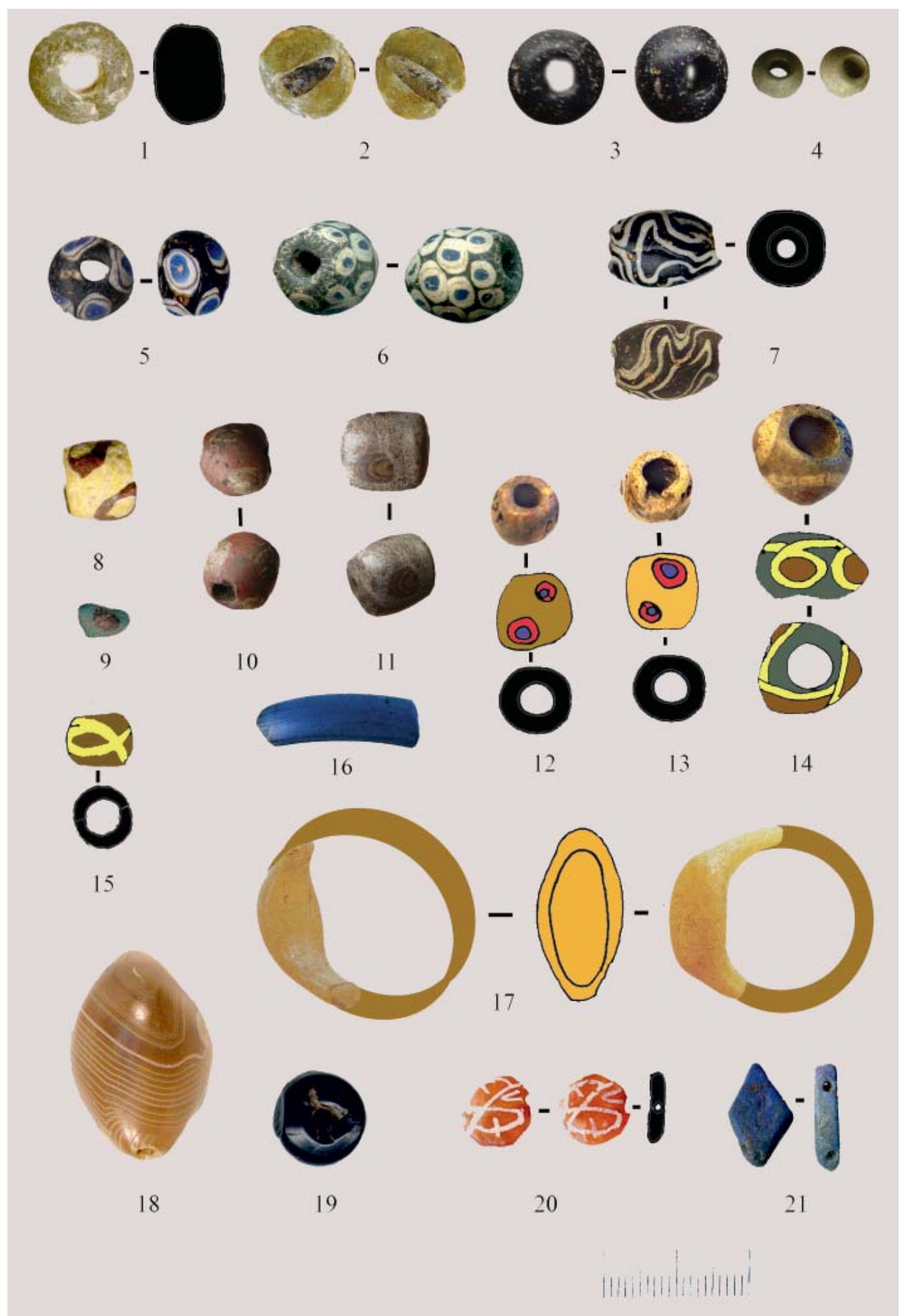

Рис. 3. Остолоповское селище. Украшения из стекла (1-17) и камня (18-21). Бусы $(1-15,18,20)$, браслет (16), перстень (17), пронизка (21). 1, 5-9, 12-21: подъемный материал. 2: раскоп XXI, 4: раскоп XVIII, уч. 15, пл.3, слой IIIp; 10: раскоп XVIII, уч. 15, пл. 1, слой II-III; 11: раскоп XVIII, уч.7, пл.3, слой IIIр. 1-17 - стекло; 18 - агат; 19 - гешир; 20 - сердолик; 21 - лазурит

Fig. 3. Ostolopovo village. Jewelry made of glass (1-17) and stone (18-21). Beads (1-15, 18, 20), bracelet (16), ring (17), thread (21). 1, 5-9, 12-21: excavated material. 2: Excavation XXI, 4: Excavation XVIII, plot 15, area 3, layer IIIp; 10: Excavation XVIII, area 15, area 1, layer II-III; 11: Excavation XVIII, section 7, area 3, layer IIIp. 1-17 - glass; 18 - agate; 19 - quishr; 20 - carnelian; 21 - lapis lazuli

Европы в целом. В Прикамье часть глазчатых (рис. 3: 5, 6). Первая из них (d=10 мм) (рис. бусин, близких по дизайну, встречается с Х в. 3: 5) круглая, зонная, с отверстием диаметром (Иванова, Куликов, 2000, с. 100-101, кат. 213). 3 мм, изготовлена из черного глухого стекла Выделяются бусы темного цвета со слои- с овальными слоистыми «глазками» белостыми круглыми или овальными «глазками» го цвета с синим центром и черной обводкой 


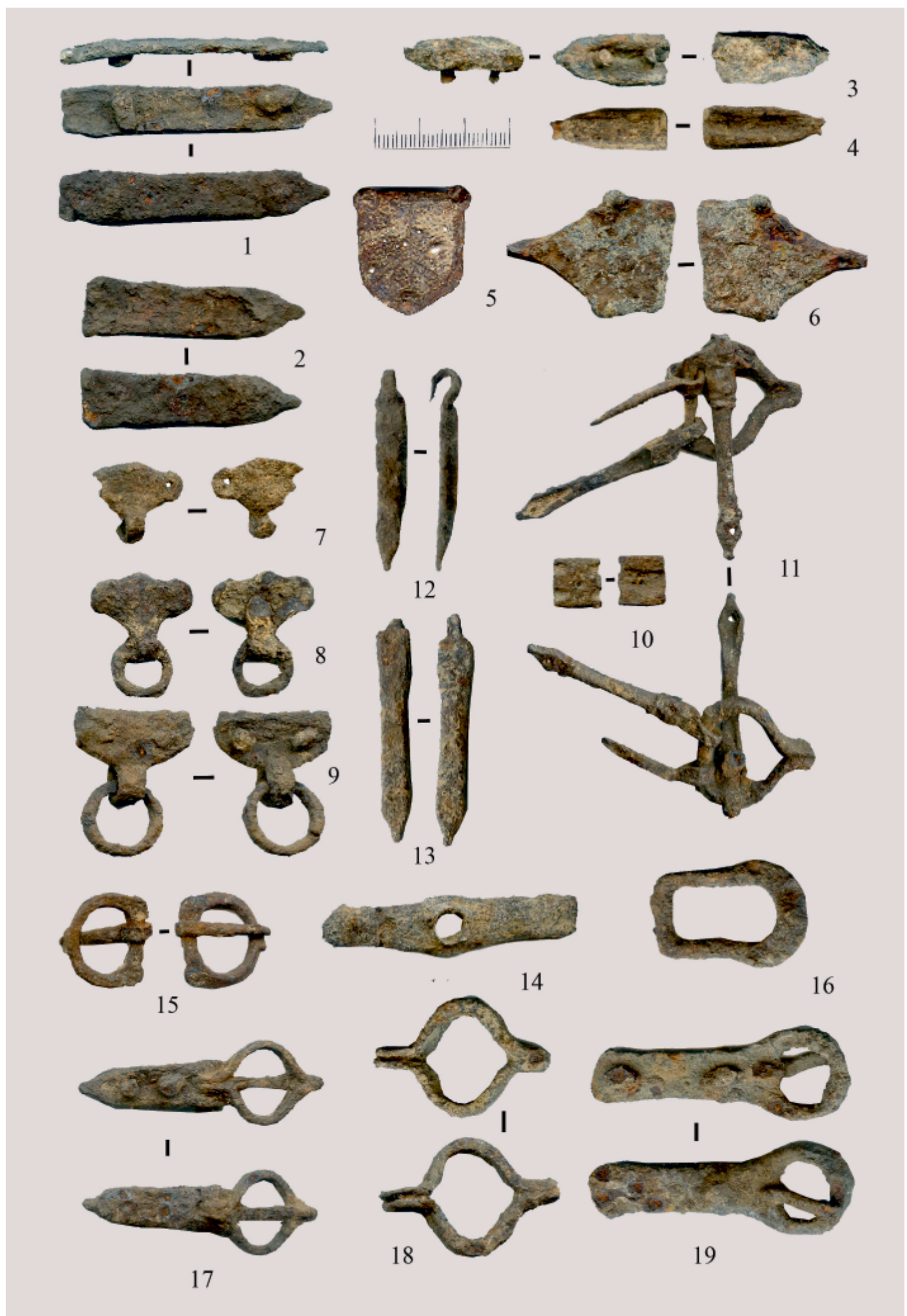

Рис. 4. Остолоповское селище. Подъемный материал. Изделия из железа. Накладки (1-5,7-10), пряжки (11,15-19), привески (12,13), наносный султан (14)

Fig. 4. Ostolopovo village. Excavated material. Iron products. Overlays (1-5,7-10), buckles (11, 15-19), pendants $(12,13)$, applied sultan (14)

последнего (техника миллефиори). Вторая бусина (d=15; h=13,65 мм) боченковидная, ближе к эллипсоидной, круглая с отверстием на входе с диаметром канала 3 мм и на выходе 1,2 мм, изготовлена вытягиванием стеклянной палочки с последующим наложением «глазков», выполненных в технике миллефиори (миниатюрной мозаики). Затем изделие было подвергнуто обкатке. По мнению Е.К. Столяровой, эта бусина египетского производства 
и датируется первой четвертью XI в. (Столярова, 2005, с. 59). Более ранние типы таких бусин встречаются в IX-X вв. (например, Больше-Тарханский могильник, погребение 75: НМ РТ, инв. № 12225; БТМ-57/206). Бусы этого типа имели широкое распространение на Ближнем Востоке в X-XI вв., например, были обнаружены при раскопках в Нишапуре (Kröger, 1995, p. 199, 200, cat. 284). Близкие по типу бусы зафиксированы в могильниках $\mathrm{X}$ XI вв. поволжско-финского населения: Beceловского, «Нижняя стрелка» (Никитина, 2012, с. 396,397 , рис. 290: 4; 291: 18).

Другой тип - бусина веретеннообразная, круглая с декором из тонких белых нитей на черном фоне (рис. 3: 7), сделанная способом навивки. По материалам могильников Верхнего Прикамья датируются такие бусы XI-XII вв. (Голдина, Королева, 1983, табл., тип 137). Аналогичная найдена на раскопе VI (ров) Кирменьского городища (Нигамаев, 2005, рис. 98: 12). Известны они в Биляре.

Из стекла были изготовлены очень редкие изделия: перстень и браслет. Перстень (рис. 3: 16) щитковый, сомкнутый $(2,5 \times 1,5 \times 1 \mathrm{~cm})$, с шинкой полуовального сечения $(0,4 \times 0,3 \mathrm{~cm})$ и плоским щитком миндалевидной формы $(2 \times 1 \mathrm{~cm})$. Диаметр внутренней части 1,8 см. Стекло желтое, прозрачное. Сделан перстень литьем в форму (Столярова, 2005 , с. 54 , рис. $1: 39)$. Браслет $(2 \times 0,7 \times 0,3$ см $)$ (рис. 3: 17) сине-фиолетового цвета изготовлен из прозрачного стекла путем вытягивания через форму с последующей «опрессовкой» на плоской плите; окончания браслета скреплялись при помощи сварки. Диаметр его 6 см; сечение треугольное (Столярова, 2005 , с. 58 , рис. 1: 35). Е.К. Столярова, исследовав браслет и перстень, пришла к выводу, что они оба византийского производства и датируются XI в., вероятно, первой четвертью этого столетия (Столярова, 2005, с. 57, 58). Аналогичные изделия византийского производства встречены в культурном слое Гнездовского поселения второй половины $\mathrm{X}$ в., также встречаются они и на Киевском Подоле с середины XII в. (Мурашева, Довгалюк, Фетисов, 2010, с. 517; Журухина, 2015, с. 219, 220, рис. II, III).

Каменные украшения немногочисленны. Крупная бусина $(\mathrm{d}=19, \mathrm{~h}=30$ мм) с продольным отверстием диаметром 2 мм (рис. $3: 18$ ) и весом 12,11 г выточена из агата. Она эллипсоидной формы, круглая в сечении, кремового цвета с белыми прожилками. Такие бусы были популярны на Востоке в Х в. Халце- доновая бусина такой же формы встречена в могильнике Саркела - Белой Вежи (Артамонова, 1963, с. 64, рис. 49: 8д). На домонгольских булгарских поселениях редки. Гагатовая бусина шаровидная, круглая, диаметром 9 мм, с отверстием диаметром 3 мм. На булгарских памятниках XI-XII вв. такие бусы практически не встречаются, хотя в Х в. они известны в захоронениях Танкеевского могильника.

Кроме бус на селище была найдена лазуритовая пронизка (рис. 3: 21): имеет вид плоской пластины правильной ромбической формы $(1,5 \times 0,9 \times 0,3 \mathrm{~cm})$. На торцевой стороне её в верхней и нижней части имеются два маленьких сквозных отверстия. Относится к типу III A-1 (по К.А. Руденко); на других памятниках Волжской Булгарии не встречается (Руденко, 2014 , с. 228, рис. 4-13). Наиболее близкие аналогии пронизке имеются в могильнике Саркела - Белой Вежи, функционировавшем в конце X - начале XII в. (Артамонова, 1963, с. 64, рис. 49: 7a).

Среди находок 1980-х и 1990-х гг. особый интерес представляют поясные пластинчатые застежки южносибирского происхождения со следами плакировки серебром (рис. 4: 6) (Казаков, 1997, рис. 7: 8; Руденко, 2001, табл. ХXX: 1, кат. 537). Помимо неё, были найдены две разнотипные накладки со следами серебряной плакировки (Руденко, 2001, с. 193, табл. XXIII: 14-16; XXX: 1, 2, кат. № 490-492,537), одна из которых была геральдической формы (рис. 4: 5). Эти предметы имеют аналогии в древностях аскизской культуры Южной Сибири (Кызласов, 1983, с. 50, 51, рис. 26). Дополняют их булгарские подражания аскизским изделиям (рис. 4: 14, 7-13, 15-19), некоторые из которых были декорированы циркульным орнаментом (Казаков, 1997, с. 75, рис. 7: 2, 3, 6-8). Аналогичные последним были найдены на Измерском селище и Билярском городище (Казаков, 1997, рис. 7: 5, 6; Руденко, 2001, с. 161, табл. IV: 15; VI: 9). Все они датируются второй половиной XI - первой половиной XII вв.

Завершая анализ подъемного материала, отметим, изученную в 2015 г., хозяйственную яму с набором целых форм и археологически целых керамических изделий (рис. 5), Она находилась в 30 м от раскопа XVI, где было обнаружено донце парфюмерного сосуда. На нем же была выявлена небольшая яма с несколькими целыми керамическими мисками, а рядом с ним - яма с человеческими останками. Все эти объекты находились на задворках обширной усадьбы, размытой водо- 

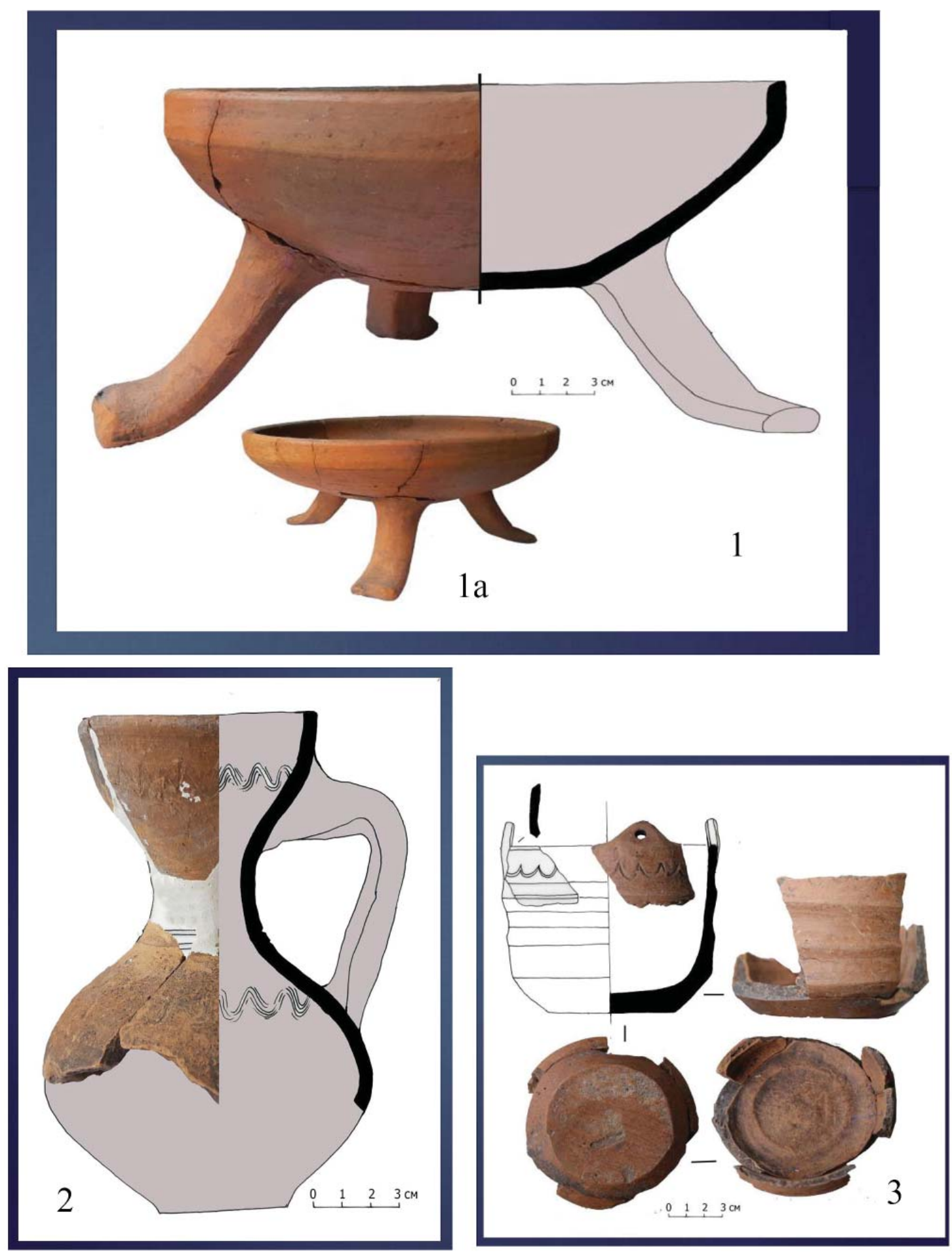

Рис. 5. Остолоповское селище. Круговая керамика из ямы «А» (2015 г.). Реконструкция К.А. Руденко

Fig. 5. Ostolopovo village. Ceramics made on a potter's wheel from pit "A" (2015). Reconstruction by K.A. Rudenko

хранилищем, и материалы с которой были рассмотрены выше.

Таким образом, анализ находок с разрушенной части Остолоповского селища показал, что они укладываются в рамки XI-XII в., а если учитывать полный хронологический диапазон бытования этих артефактов, то и конец X в. Поскольку часть усадьбы, которая в 1980-е гг. разрушалась водохранилищем, удалось исследовать раскопками в 1997-2017 г., то можно сопоставить эти данные с теми материалами, которые дали эти раскопки с учетом стратиграфии памятника.

Интересующая нас западная часть селища изучалась в 1997-2006 и 2017 гг. - раскопы I, III, IV, VI-XIV, XVI, XXIV. За исключением раскопов III, XIV, XXIV, остальные продолжали предыдущие, то есть прибрежная зона вскрывалась сплошной площадью. В юго-восточной части памятника в 1997 , 2007-2011 гг. были разбиты раскопы II, V, XVII-XXIII. Раскопки показали, что мощность 
культурных отложений на селище вне сооружений не превышает 70 см и составляет в среднем 50-60 см (Руденко, 2012, с. 137, рис. 2: 3, 4; Руденко, 2017, с. 296-319). Стратиграфическая градация культурного слоя отличает Остолоповское селище от других булгарских поселений домонгольского времени, исследованных к настоящему времени (Казаков, 1991, с. 27).

Культурный слой селища сформировался на черноземе (погребенная почва), который прослеживается на территории всего памятника. Выделяются пять слоев, которые датированы находками. Они следующие: слой I: XX - начало XXI в.; слой II: первая - вторая треть XII в.; слой ІІІп (третий поздний): вторая половина XI в. - начало XII в.; слой IIIp (третий ранний): начало XI в. - первая половина XI в.; слой IV: рубеж X-XI в. - начало XI в.; слой V: погребенная почва. Слой IV по факту - это верхний горизонт слоя V. Датировка слоев рассмотрена нами в отдельной статье (Руденко, 2017, с. 299-307).

Наиболее мощными являются отложения III слоя. Они разделяются на два горизонта - из-за произошедшего ближе к середине XI столетия пожара (или пожаров), от которого пострадали усадьбы селища. Этот слой наиболее представителен в западной части поселения. В восточной части он прослеживается участками. В северной и северо-восточной части селища основные отложения относятся ко II слою. В последней трети XI - начале XII в. селище было практически полностью разорено, а многие жители погибли. Их останки были обнаружены в котлованах жилищ, например, в постройке 1 раскопа I (Руденко, 2002, с. 36), или рядом с ними; причем людей, в основном мужчин в возрасте от 25 до 45 лет и подростков, убивали очень жестоко (Руденко, 2009, с. 5-15; Руденко, 2010, с. 202-224; Руденко, 2011a, с. 12-15; Гатауллина, Руденко, c. 217-218). К этому периоду относится часть находок предметов вооружения и конского снаряжения как из раскопок, так и из подъемного материала (Руденко, 2002, с. 40, рис. 6: 7, 10-14; 7: 38, 39). Этими событиями завершается формирование III слоя. Спустя какое-то время жизнь на поселении возобновилась, но в основном на незастроенной части территории (рис. 2: 4). В этот период сформировался II стратиграфический слой. К концу XII в., а может быть и чуть раньше селище угасло. После этого это место не обживалось и не распахивалось, что сохранило сформировавшийся культурный слой без существенных повреждений до настоящего времени (Руденко, 2017, с. 296-319.).

Из вышесказанного становится очевидным, что подъемный материал и материалы раскопок в хронологическом плане идентичны. То есть разрушенный участок памятника не являлся его ранней частью. Застройка поселения началась с юго-юго-восточного побережья останца, где протекала Шенталка (рис. 1:4).

В заключение отметим, что в подъемном материале встречены находки не только булгарского времени: на размыве в северной части собрана коллекция кремниевых изделий и фрагменты керамики эпохи бронзы. На западном побережье были обнаружены артефакты эпохи раннего железного века. Интересны несколько предметов, относящихся ко второй половине I тыс. н. э. Это сердоликовая плоская $(8,35 \times 9,37 \times 2,88$ мм) бусина с росписью (Руденко, 2002, с. 52, рис. 7: 35; 2012, с. 133, рис. 7: 13). С обеих её сторон имеется рисунок, выполненный белыми тонкими линиями в виде бабочки (рис. 3: 20). Она близка типу ХІБІ бус неволинской культуры по типологии Е.В. Голдиной и может быть датирована VI-VIII в. (Голдина, 2010, с. 44, 138, 146, рис. 28, 36). К VI-VII вв. относится бронзовая кольцо-пряжка овальной формы также из подъемного материала. Эти находки, очевидно, не связаны с булгарским поселением XI-XII в.

Таким образом, Остолоповское селище функционировало с рубежа X-XI в. и до последней трети XII в. Это подтверждается и планиграфией поселения (рис. 1: 4). Останец заселялся с юго-восточной стороны в северозападном направлении к острию мыса. Это было обусловлено тем, что именно с юговосточной стороны останца в то время протекала река Шенталка. Северо-восточное побережье, вероятно, было менее удобным для проживания из-за дальности подходов к реке и осваивалось позже по мере роста поселения. Самые ранние находки из слоя IIIр и IV, как и находки в подъемном материале, относятся к рубежу X-XI или началу XI в. (Руденко, 2017, c. $303,306,307)$.

\section{ЛИТЕРАТУРА}

Артамонова О.А. Могильник Саркела - Белой Вежи // Труды Волго-Донской археологической экспедиции. Том ІІІ / МИА. № 109 /Отв. ред. М.И. Артамонов. М.; Л.: Изд-во АН СССР, 1963. С. 5-215. 
Археологические памятники Центрального Закамья / Отв. ред. А.Х. Халиков. Казань: ИЯЛИ КФАН CCCP, $1988.98 \mathrm{c}$.

Архипов Г.А. Марийцы ХІІ-ХІІІ вв. (к этнокультурной истории Поветлужья). Йошкар-Ола: Марийское книжное издательство, 1986. 115 с.

Беговатов Е.А., Полубояринова М.Д. Восточные стеклянные лампы из Поволжья // РА. 2014. №1. C. $158-162$.

Белавин А.М., Крыласова Н.Б. Огурдинский могильник. Пермь: ПГГПУ, 2012. 259 с.

Гайнуллин И.И., Дёмина Ю.В., Усманов Б.М. Опыт применения ГИС-технологий для оценки интенсивности разрушения археологических памятников в зоне влияния Куйбышевского водохранилища // КСИА. 2012. Вып. 226. С. 54-63.

Голдина Е.В. Бусы могильников неволинской культуры (конец IV-IX вв.) // МИКВАЭ. Т. 6. Ижевск: Удмуртский государственный университет, 2010. 264 с.

Голдина Р.Д., Королева О.П. Бусы средневековых могильников Верхнего Прикамья // Этнические процессы на Урале и в Сибири в первобытную эпоху / Отв. ред. В.Е. Владыкин. Ижевск: Удм. ун-т, 1983. C. $40-72$.

Доброва О.П. Стеклянные бусы Гнёздово по материалам раскопок Центрального городища // Гнёздовский археологический сборник. Материалы и исследования. Вып. 1 / Труды ГИМ. Вып. 210 / Отв. ред. С.Ю. Каинов. М.: ГИМ, 2018. С. 102-126.

Журухина Е.Ю. Украшения из стекла: тенденции и проблемы исследования находок Киевского Подола // Стекло Восточной Европы с древности до начала XX века / Отв. ред. П.Г. Гайдуков, сост. Е.К. Столярова. М.: Нестор-История, 2015. С. 218-222.

Захаров С.Д. Древнерусский город Белоозеро. М.: Индрик, 2004. 592 с.

Иванова М.Г. Иднакар: Древнеудмуртское городище IX-XIII вв.: Монография. Ижевск: УИИЯЛ УрО РАН, 1998. 294 c.

Иванова М.Г., Куликов К.И. Древнее искусство Удмуртии. Ижевск: УдмИИЯЛ УрО РАН, 2000. 216 с.

Казаков Е.П. Булгарское село X-XIII веков низовий Камы. Казань: Татар. кн. изд-во, 1991. 176 с.

Казаков Е.П. Об этнокультурных компонентах народов юго-восточной Европы в Волжской Болгарии (по археологическим материалам) // ТА. 1997. №1. С. 61-77.

Крыласова Н.Б. Археология повседневности: материальная культура средневекового Предуралья. Пермь: ПГПУ, 2006. 352 с.

Кызласов И.Л. Аскизская культура Южной Сибири X-XIV вв. // САИ. Вып. Е3-18. М.: Наука, 1983. $128 \mathrm{c}$.

Леонтьев А.Е. Археология мери. К предыстории Северо-Восточной Руси. М.: Геоэко, 1996. 341 с.

Мурашева В.В., Довгалюк Н.П., Фетисов А.А. Византийские импорты с территории пойменной части Гнездовского поселения // «Краеугольный камень». Археология, история, искусство, культура России и сопредельных стран. Т. 1 / Ред. Е.Н. Носов, С.В. Белецкий. СПб: Ломоносовъ, 2010. С. 512-536.

Нигамаев А.З. Болгарские города Предкамья: Алабуга, Кирмень, Чаллы: Своеобразие материальной культуры населения. Казань: Изд-во Казанск. ун-та, 2005. 228 с.

Никитина Т.Б. Погребальные памятники IX-XI вв. Ветлужско-Вятского междуречья // Археология Евразийских степей. Вып. 14. Казань: Отечество, 2012. 408 с.

Полубояринова М.Д. Украшения из цветных камней Болгара и Золотой Орды. М.: ИА АН СССР, 1991. $112 \mathrm{c}$.

Путешествие ибн Фадлана: Волжский путь от Багдада до Булгара. Каталог выставки. М.: Издательский дом Марджани, 2016. 560 с.

Руденко К.А. Тюркский мир и Волго-Камье в XI-XIV вв.: Изделия аскизского круга в Среднем Поволжье. Казань: Заман, 2001. 256 с.

Руденко K.A. Волжская Булгария в системе торговых путей средневековья (по материалам раскопок Речного (Остолоповского) селища в Алексеевском районе Татарстана) // Великий Волжский путь: история формирования и развития. Материалы круглого стола / Отв. ред. М.А. Усманов Часть II, Казань: ИИ АН РТ, 2002. С. 31-52.

Руденко K.A. О некоторых итогах исследования Остолоповского селища в Алексеевском районе Республики Татарстан // Поволжская археология. 2012. №2. С. 123 - 145.

Руденко К.А. Украшения из лазурита XI - XIII вв. из Волжской Булгарии и древности Сибири // Древности Сибири и Центральной Азии. 2014. № 7(19). С. 224-244. 
Руденко K.A. О защитном вооружении булгарского воина XI в. (по материалам булгарского селища (Остолоповского) у с. Речное) // Военная археология. Вып.3 / Отв. ред. О.В. Двуреченский. М.; Тула: МедиаМир; Куликово поле, 2014а. С. 47-54.

Руденко К.А. Исследования VI Алексеевского и Мурзихинского селищ в Татарстане в 1992-1996 г. Казань: Издательский дом «Казанская недвижимость», 2015. 400 с.

Руденко K.A. Стратиграфия Остолоповского селища XI - XII вв. в Алексеевском районе Татарстана // Археология Евразийских степей. 2017. №1. С. 296-319.

Руденко К.А. Новые данные о булгарских жилищах домонгольского времени (по материалам Остолоповского селища в Татарстане // Археология Евразийских степей. 2019. №6. С. 95-110 https://doi. org/10.244.11/2587-6112-2019-00082.

Седова М.В. Ювелирные изделия древнего Новгорода (X-XV вв.). М.: Наука, 1981. 196 с.

Старая Ладога - древняя столица Руси. Каталог выставки / Науч. ред. Б.С. Короткевич. СПб.: Изд-во ГЭ, 2003. $190 \mathrm{c}$.

Старостин П.Н. Раннее поселение на правом берегу Малого Иерусалимского оврага в Болгарах // Археология Волжской Булгарии: проблемы, поиски, решения / Отв. ред. Ф.Ш. Хузин. Казань: ИЯЛИ КФАН СССР, 1993. С. 53-63.

Столярова Е.К. Стеклянные украшения булгарских селищ низовий Камы // Древности Поволжья: эпоха средневековья (исследования культурного наследия Волжской Булгарии и Золотой Орды) / Отв. ред. К.А. Руденко. Казань: Школа, 2005. С. 43-66.

Столярова Е.К. Стеклянный сосуд из раскопок Остолоповского селища // Материалы Лихачевских чтений Национального музея РТ. Казань: ООО ИПЦ «Экспресс-формат», 2008. С. 272-277.

Фехнер М.В. Предметы косторезного производства // Ярославское Поволжье Х-XI вв. по материалам Тимеревского, Михайловского и Петровского могильников / Отв. ред. А.П. Смирнов.М.: ГИМ, 1963. С. 39-42.

Хлебникова Т.А. Отчет о работах Отряда археологической экспедиции по исследованию болгарских поселений зоны Куйбышевского водохранилища в 1969 году. Казань, 1970 г. / Архив ИА РАН. Р-I. №3919. 75 л.

Хлебникова T.A. Некоторые итоги исследования булгарских памятников нижнего Прикамья // СА. 1974. № 1. C. 58-68.

Хлебникова Т.А., Казаков Е.П. К археологической карте ранней Волжской Болгарии на территории ТАССР // Из археологии Волго-Камья / Отв. ред. А.Х. Халиков. Казань: ИЯЛИ КФАН СССР, 1976. C. $109-136$.

Энговатова А.В., Коваль В.Ю., Зои Е.П., Столярова Е.К., Сарачева Т.Г. Мякининские курганы. Мякининский археологический комплекс в Подмосковье / Материалы спасательных археологических исследований. Т. 21. М.: ИА РАН, 2018. 344 с.

Carboni S. Glass from Islamic Lands. The al-Sabah Collection, Dar al-Athar al-Islamiyyah, Kuwait National Museum. L.: Thames \& Hudson, 2001. 416 p.

Carboni S., Waitehouse D. Glass of the Sultans. N.-Y.: Metropolitan Museum of Art, 2002. 330 p.

Kröger Jens Nishapur. Glass of th Early Islamic Period. N.-Y.: Metropolitan Museum of Art, 1995. 258 p.

\section{Информация об авторе:}

Руденко Константин Александрович, доктор исторических наук, профессор, Казанский государственный институт культуры (г. Казань, Россия); murziha@mail.ru

\section{REFERENCES}

Artamonova, O. A. 1963. In Artamonov, M. I. (ed.). Materialy i issledovaniia po arkheologii SSSR (Materials and Research in the USSR Archaeology) 109. Moscow; Leningrad: the USSR Academy of Sciences, 5-215 (in Russian).

Khalikov, A. Kh (ed.). 1988. Arkheologicheskie pamiatniki Tsentral'nogo Zakam'ia (Archaeological Monuments of the Central Trans-Kama Region). Kazan: Institute of Language, Literature and History, Kazan Branch of the USSR Academy of Sciences (in Russian).

Arkhipov, G. A. 1986. Mariitsy XII-XIII vv. (ketnokul 'turnoi istorii Povetluzh'ia) (Mari People in $12^{\text {th }}-13^{\text {th }}$ Centuries: to the Ethno-Cultural History of the Vetluga River Basin). Yoshkar-Ola: "Mariiskoe knizhnoe izdatel'stvo" Publ. (in Russian).

Begovatov, E. A., Poluboiarinova, M. D. 2014. In Rossiiskaia Arkheologiia (Russian Archaeology) (1), $158-162$ (in Russian). 
Belavin, A. M., Krylasova, N. B. 2012. Ogurdinskii mogil'nik (Ogurdino Burial Ground). Perm: Perm State Humanitarian Pedagogical University (in Russian).

Gainullin, I. I., Demina, Yu. V., Usmanov, B. M. 2012. In Kratkie soobshcheniia Instituta arkheologii (Brief Communications of the Institute of Archaeology) 226. 54-63 (in Russian).

Goldina, E. V. 2010. Busy mogil'nikov nevolinskoi kul'tury (konets IV-IX vv.) (Beads from the Nevolino Culture Burial Grounds (Late $4^{\text {th }}-9^{\text {th }}$ Centuries)). Series: Proceedings and Research of the Kama-Vyatka Archaeological Expedition 6. Izhevsk: Udmurt State University (in Russian).

Goldina, R. D., Koroleva, O. P. 1983. In Vladykin, V. E. (ed.). Etnicheskie protsessy na Urale i Sibiri v pervobytnuiu epokhu (Ethnic Processes in the Urals and Siberia in the Prehistoric Age). Izhevsk: Udmurt State University, 40-72 (in Russian).

Dobrova, O. P. 2018. In Kainov, S. Yu. (ed.). Gnezdovskiy arkheologicheskiy sbornik. Materialy i issledovaniya (Gnezdovsky Archaeological Collection. Materials and Research) 1. Series: Proceedings of the State Historical Museum 210. Moscow: State Historical Museum, 102-126 (in Russian).

Zhurukhina, E. Yu. 2015. In Gaidukov, P. G. (ed.). Steklo Vostochnoi Evropy s drevnosti do nachala XX veka (East European Glass from Antiquity to the Early 20 th Century). Moscow: "Nestor-Istoriia"Publ., 218-222 (in Russian).

Zakharov, S. D. 2004. Drevnerusskii gorod Beloozero (The Old Rus Town of Beloozero). Moscow: "Indrik" Publ. (in Russian).

Ivanova, M. G. 1998. Idnakar: Drevneudmurtskoe gorodishche IX-XIII vv. (Idnakar: Ancient Udmurt Hillfort of $9^{\text {th }}-13^{\text {th }}$ Centuries). Izhevsk: Udmurtian Institute of History, Language, and Literature, Ural Branch of the Russian Academy of Sciences (in Russian).

Ivanova, M. G., Kulikov, K. I. 2000. Drevnee iskusstvo Udmurtii (Ancient Art of Udmurtia). Izhevsk: Udmurtian Institute of History, Language and Literature, Ural Branch of the Russian Academy of Sciences (in Russian).

Kazakov, E. P. 1991. Bulgarskoe selo X-XIII vekov nizovii Kamy $\left(10^{\text {th }}-13^{\text {th }}\right.$ Century Bulgar Village in the Lower Kama Region). Kazan: “Tatarskoe knizhnoe izdatel'stvo" Publ. (in Russian).

Kazakov, E. P. 1997. In Tatarskaia arkheologiia (Tatar Archaeology) (1), 61-77 (in Russian).

Krulasova, N. B. 2006. Arkheologiia povsednevnosti: material'naia kul'tura srednevekovogo Predural'ia (Archaeology of Everyday Life: Material Culture of the Medieval Cis-Urals). Perm: Perm State Pedagogical University (in Russian).

Kyzlasov, I. L. 1983. Askizskaya kul'tura Yuzhnoy Sibiri X-XIV vv. (Askiz Culture of South Siberia in the 10 th $-14^{\text {th }} c c$.). Series: Svod Arkheologicheskikh Istochnikov (Corpus of Archaeological Sources) E3-18. Moscow: "Nauka" Publ. (in Russian).

Leont'ev, A. E. 1996. Arkheologiia meri. K predystorii Severo-Vostochnoi Rusi (Archaeology of the Merya People. Towards Pre-History of North-Eastern Rus'). Moscow: "Geoeko" Publ. (in Russian).

Murasheva, V. V., Dovgaliuk, N. P., Fetisov, A. A. 2010. In Nosov, E. N., Beletsky, S. V. (eds.). Kraeugol'nyi kamen'. Arkheologiia, istoriia, iskusstvo, kul'tura Rossii i sopredel'nykh stran (Cornerstone. Archaeology, History, Art and Culture of Russia and Its Neighboring Countries) 1. Saint Petersburg: "Lomonosov" Publ., 512-536 (in Russian).

Nigamaev, A. Z. 2005. Bolgarskie goroda Predkam 'ia: Alabuga, Kirmen', Chally. Svoeobrazie material'noi kul'tury i naseleniia (Bolgar Towns of the Cis-Kama area: Alabuga, Kirmen, Chally. Originality of Material Culture and Population). Kazan: Kazan State University (in Russian).

Nikitina, T. B. 2012. Pogrebal'nye pamiatniki IX-XI vv. Vetluzhsko-Viatskogo mezhdurech'ia (Burial Sites of the $9^{\text {th }}-11^{\text {th }}$ Centuries in the Vetluga-Vyatka Interfluvial Area). Series: Arkheologiya evraziiskikh stepei (Archaeology of Eurasian Steppes) 14. Kazan: "Otechestvo" Publ. (in Russian).

Poluboiarinova, M. D. 1991. Ukrasheniia iz tsvetnykh kamnei Bolgara i Zolotoi Ordy (Jewelry of Gemstones found in Bulgar and the Golden Horde). Moscow: Academy of Sciences of the USSR, Institute for Archaeology (in Russian).

Puteshestvie ibn Fadlana: Volzhskii put' ot Bagdada do Bulgara (The Journey of Ibn Fadlan: the Volga Route from Baghdad to Bolgar). 2016. Moscow: "Izdatel'skii dom Mardzhani” Publ. (in Russian).

Rudenko, K. A. 2001. Tiurkskii mir i Volgo-Kambe v XI-XIV vv.: Izdeliia askizskogo kruga v Srednem Povolzhbe (Turkic World and the Volga-Kama Region in the $11^{\text {th }}-14^{\text {th }}$ cc.: Articles of the Askiz Range in the Middle Volga Kegion). Kazanь: "Zaman” Publ. 141 (in Russian).

Rudenko, K. A. 2002. In Usmanov, M. A. (ed.). Velikii Volzhskii put': istoriia formirovaniia i razvitiia (The Great Volga Route: Formation and Development History) 2. Kazan: Institute for History named after Sh. Marjani, Tatarstan Academy of Sciences, 31-52 (in Russian). 
Rudenko, K. A. 2012. In Povolzhskaya arkheologiya (Volga River Region Archaeology) (2), 123-145 (in Russian).

Rudenko, K. A. 2014. In Drevnosti Sibiri i Tsentral'noi Azii (Antiquities of Siberia and Central Asia) 19 (7). 224-244 (in Russian).

Rudenko, K. A. 2014a. In Dvurechensky, O. V. (ed.). Voennaia arkheologiia. (Military Archaeology). 3 Moscow; Tula: "MediaMir" Publ., "Kulikovo Pole" State Museum-Reserve, 47-54 (in Russian).

Rudenko, K. A. 2015. Issledovaniia VI Alekseevskogo i Murzikhinskogo selishch v Tatarstane v 1992-1996 g. (Studies of VI Alekseevskoye and Murzikha Settlements in Tatarstan in 1992-1996). Kazan: "Kazanskaia nedvizhimost" Publ. (in Russian).

Rudenko, K A. 2017. In Arkheologiia Evraziiskikh stepei (Archaeology of Eurasian Steppes) 1, 296-319. (in Russian).

Rudenko, K A. 2019. In Arkheologiia Evraziiskikh stepei (Archaeology of Eurasian Steppes) 6, 95-110. DOI: https://doi.org/10.244.11/2587-6112-2019-00082. (in Russian).

Sedova, M. V. 1981. Iuvelirnye izdeliia drevnego Novgoroda (X-XV vv.) (Jewelry of Old Novgorod (1 $0^{\text {th }}$ $15^{\text {th }}$ Centuries)). Moscow: "Nauka" Publ. (in Russian).

Korotkevich, B. S. 2003 (ed.). Staraia Ladoga - drevniaia stolitsa Rusi (Staraya Ladoga - the Ancient Capital of Rus). Saint Petersburg: The State Hermitage Museum (in Russian).

Starostin, P. N. 1993. In Khuzin, F. Sh. (ed.). Arkheologiia Volzhskoi Bulgarii: problemy, poiski, resheniia (Archaeology of the Volga Bulgaria: Problems, Research, Answers). Kazan: Institute of Language, Literature and History named after G. Ibragimov, Kazan Branch of the USSR Academy of Sciences, 53-63 (in Russian).

Stolyarova, E. K. 2005. In Rudenko, K. A. (ed.). Drevnosti Povolzh'ia: epokha srednevekov'ia (issledovaniia kul'turnogo naslediia Volzhskoi Bulgarii i Zolotoi Ordy) (Antiquities of the Volga Region: the Medieval Period (Studies of the Cultural Heritage of Voga Bolgaria and the Golden Horde)). Kazan: "Shkola" Publ., 43-66 (in Russian).

Stolyarova, E. K. 2007. In Materialy Likhachevskikh chteniy (Proceedings of Likhachev Readings) Kazan': "Ekspert-format" Publ., 272-277 (in Russian).

Fekhner, M. V. 1963. In Smirnov, A. P. (ed.). Iaroslavskoe Povolzh'e X-XI vv. po materialam Timerevskogo, Mikhailovskogo i Petrovskogo mogil'nikov (Yaroslavl Volga Region of the $10^{\text {th }}-11^{\text {th }} \mathrm{cc}$. based on materials from Timerevo, Mikhailovo and Petrovsky burial grounds). Moscow, 39-42 (in Russian).

Khlebnikova, T. A. 1970. Otchet o rabotakh Otriada arkheologicheskoi ekspeditsii po issledovaniiu bolgarskikh poselenii zony Kuibyshevskogo vodohranilishcha v 1969 godu (Report on the Work of the Archaeological Expedition Group for the Exploration of Bolgar Settlements in the Kuybyshev Reservoir Area in 1969). Kazan. Archive of the Institute of Archaeology of the Russian Academy of Sciences. Inv. R-1, dossier 3919 (in Russian).

Khlebnikova, T. A. 1974. In Sovetskaia Arkheologiia (Soviet Archaeology) (1), 58-68 (in Russian).

Khlebnikova, T. A., Kazakov, E. P. 1976. In Khalikov, A. Kh. (ed.). Iz arkheologii Volgo-Kam 'ia (From the Volga-Kama Archaeology). Kazan: Institute for Language, Literature and History, Kazan Branch of the USSR Academy of Sciences, 109-136 (in Russian).

Engovatova, A. V., Koval, V. Yu., Zots, E. P., Stolyarova, E. K., Saracheva, T. G. 2018. Miakininskii arkheologicheskii kompleks v Podmoskov'e (Myakinino Barrows. Myakinino Archaeological Complex in the Moscow Region). Series: Materialy spasatel'nykh arkheologicheskikh issledovaniy (Materials of Rescue Archaeological Studies) Moscow: Institute of Archaeology of the Russian Academy of Sciences (in Russian).

Carboni S. 2001. Glass from Islamic Lands. The al-Sabah Collection, Dar al-Athar al-Islamiyyah, Kuwait National Museum. L.: Thames \& Hudson (in English).

Carboni S., Waitehouse D. 2002. Glass of the Sultans. N.-Y.: Metropolitan Museum of Art )in English).

Kröger Jens 1995. Nishapur. Glass of the Early Islamic Period. N.-Y.: Metropolitan Museum of Art (in English).

\section{About the Author:}

Rudenko Konstantin A. Doctor of Historical Sciences. Professor, Kazan State Institute of Culture. Orenburgsky Trakt St., 3, Kazan, 420059, Russian Federation; murziha@mail.ru 